\title{
BMJ Open Qualitative investigation into a wearable system for chronic obstructive pulmonary disease: the stakeholders' perspective
}

\author{
Reem Kayyali, ${ }^{1}$ Vilius Savickas, ${ }^{1}$ Martijn A Spruit, ${ }^{2}$ Evangelos Kaimakamis, ${ }^{3}$ \\ Roshan Siva, ${ }^{4}$ Richard W Costello, ${ }^{5}$ John Chang, ${ }^{4}$ Barbara Pierscionek, ${ }^{1}$ \\ Nikki Davies, ${ }^{4}$ Anouk W Vaes, ${ }^{2}$ Rita Paradiso, ${ }^{6}$ Nada Philip, ${ }^{1}$ Eleni Perantoni, ${ }^{4}$ \\ Shona D'Arcy, ${ }^{5}$ Andreas Raptopoulos, ${ }^{7}$ Shereen Nabhani-Gebara ${ }^{1}$
}

To cite: Kayyali $\mathrm{R}$,

Savickas V, Spruit MA, et al. Qualitative investigation into a wearable system for chronic obstructive pulmonary disease: the stakeholders' perspective. BMJ Open 2016;6:e011657. doi:10.1136/bmjopen-2016011657

- Prepublication history for this paper is available online. To view these files please visit the journal online (http://dx.doi.org/10.1136/ bmjopen-2016-011657)

Received 8 March 2016 Revised 23 May 2016 Accepted 17 June 2016

CrossMark

For numbered affiliations see end of article.

Correspondence to Dr Reem Kayyali; r.kayyali@kingston.ac.uk

\section{ABSTRACT}

Objectives: To ascertain the stakeholders' views and devise recommendations for further stages of the Wearable Sensing and Smart Cloud Computing for Integrated Care to Chronic Obstructive Pulmonary Disease (COPD) Patients with Co-morbidities (WELCOME) system development. This system aims to create a wearable vest to monitor physiological signals for patients concerned incorporating an inhaler adherence monitoring, weight, temperature, blood pressure and glucose metres, and a mobile health application for communication with healthcare professionals (HCPs).

Design: A study of qualitative data derived from focus groups and semistructured interviews.

Setting: 4 participating clinical sites in Greece, the UK, Ireland and the Netherlands.

Participants: Purposive sampling was used to recruit 32 patients with COPD with heart failure, diabetes, anxiety or depression, 27 informal carers and 23 HCPs from 4 European Union (EU) countries for focus groups and interviews.

Results: Most patients and HCPs described the WELCOME system as 'brilliant and creative' and felt it gave a sense of safety. Both users and HCPs agreed that the duration and frequency of vest wear should be individualised as should the mobile application functions. The parameters and frequency of monitoring should be personalised using a multidisciplinary approach. A 'traffic light' alert system was proposed by HCPs for abnormal results. Patients were happy to take actions in response.

Conclusions: WELCOME stakeholders provided valuable views on the development of the system, which should take into account patient's individual comorbidities, circumstances and concerns. This will enable the development of the individualised system in each member state concerned.

\section{INTRODUCTION}

Exacerbations of chronic obstructive pulmonary disease (COPD) are major contributors

\section{Strengths and limitations of this study}

- The strengths of this study are the insights into the individualisation of the system design that it provides and the noting of any issues or concerns that may need to be taken into account during the Wearable Sensing and Smart Cloud Computing for Integrated Care to Chronic Obstructive Pulmonary Disease (COPD) Patients with Co-morbidities (WELCOME) system development.

- These findings have broad applicability and can be extended to any telehealth and wearable systems developed for chronic conditions monitoring.

- Interviews with various stakeholders, including the service users, their carers and healthcare providers, were a strength as they allowed for triangulation which added credibility to any themes emerging from the study.

- Elderly patients over 80 years of age formed a minority of service users interviewed and may not have been representative of the demographics of the ageing COPD population.

- The study did not take into account the views of tax payers and service commissioners, which should be considered as part of the costing exercise, and only one general practitioner (GP) was involved in the interview phase even though GPs might have to lead the system implementation in primary care setting in some countries.

to healthcare expenses ${ }^{12}$ and cause distress to patients and their families. ${ }^{34}$ One-third of hospital COPD admissions could be prevented by earlier diagnosis and management. ${ }^{1}$ However, COPD is complicated by a large number of comorbidities, such as chronic heart failure $(\mathrm{CHF}),{ }^{5}$ diabetes $^{6}$ as well as symptoms of anxiety and/or depression. ${ }^{78}$ 
Advanced information technologies have made the functioning of multidisciplinary COPD management teams more feasible in recent years. ${ }^{9}{ }^{10}$ With patient telemonitoring, results or symptoms are obtained, and analysed via a predetermined decision support system. ${ }^{11-13}$ This can include informing the patient about actions to be taken or referring them to appropriate healthcare professionals (HCPs). ${ }^{14-16}$

Wearable Sensing and Smart Cloud Computing for Integrated Care to COPD Patients with Co-morbidities (WELCOME) is an innovative European Union telehealth project that aims to develop a wearable vest with sensors for the monitoring of physiological signals using cloud computing technology (figure 1). The system uses a number of patient-held devices, such as a blood glucose metre and an inhaler adherence monitoring device to assess the patient's inhaler technique. This is accompanied by a patient support system through a mobile phone application providing lifestyle advice, mental health assessment and other functions. ${ }^{17}$ The WELCOME project is currently in its third year.

The WELCOME system will be validated in patients with COPD suffering from CHF, diabetes, anxiety or depression in four countries: Greece, the UK, Ireland, and the Netherlands. It is hypothesised that continuous monitoring and detection of worsening events will lead to improved care for patients with COPD and reduced rate of hospital admissions.

The WELCOME system framework adopts a usercentred approach. For a successful system design, user requirements of key stakeholders from each of the validating countries were determined following focus groups and interviews. The aim of this study was to confirm the current state of COPD care and determine the stakeholders' views about the overall telehealth system proposed; the vest, the mobile application, the triage service and potential monitoring parameters in order to guide the system development in each participating country.

\section{MATERIALS AND METHODS \\ Study subjects and design}

This study used a mixed-method approach eliciting perceptions of stakeholders through focus groups and interviews. Phenomenology was selected as the main methodological orientation for this study since it was aimed at determining the perceptions of stakeholders regarding the current COPD care and potential integration of technology.

Purposive sampling was used to recruit 32 patients with COPD, 27 informal carers and 23 HCPs in four countries (table 1, figure 2). Each participant was provided with an information sheet and asked to sign a consent form prior to taking part in the study.

Nine patients refused to participate in the study due to lack of interest $(n=3)$, the unfamiliarity with research procedures $(n=2)$, the unwillingness to take part in a group interview $(n=2)$, the inability to attend the focus group in the hospital setting $(n=1)$ or lack of time $(n=1)$. None of the patients dropped out of the study.

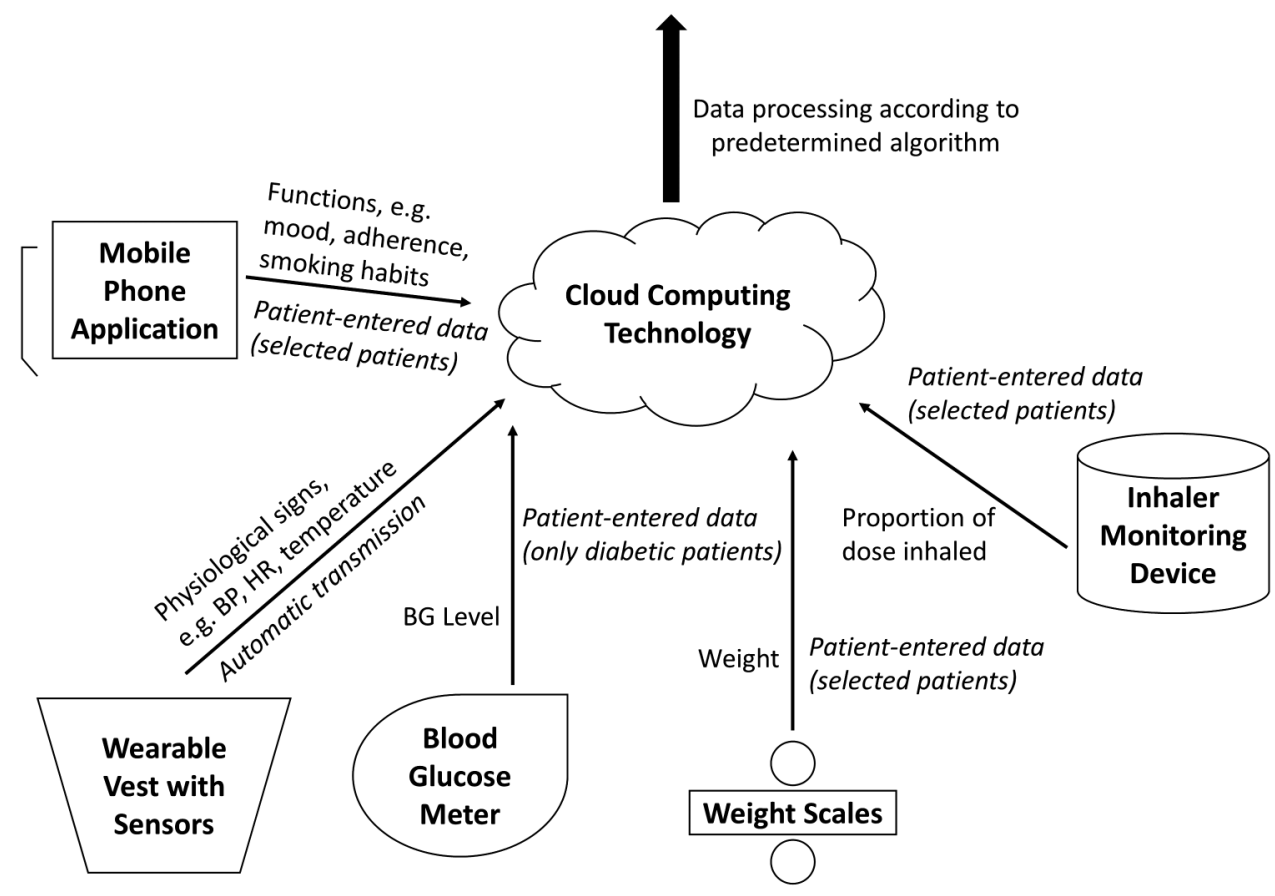

Figure 1 A summary of components involved in WELCOME system to aid data collection for further processing, reporting and appropriate action. For further information, see figure 3 below. BG, blood glucose; BP, blood pressure; HR, heart rate; WELCOME, Wearable Sensing and Smart Cloud Computing for Integrated Care to Chronic Obstructive Pulmonary Disease Patients with Co-morbidities. 
Table 1 Demographics of the patients from four countries who took part in the focus groups

\begin{tabular}{|c|c|c|c|c|c|c|c|c|c|c|c|c|c|c|}
\hline \multirow[b]{2}{*}{ Nationality } & \multirow{2}{*}{$\begin{array}{l}\text { Number of } \\
\text { patients }\end{array}$} & \multicolumn{2}{|l|}{ Sex } & \multicolumn{4}{|c|}{ Age group } & \multicolumn{7}{|c|}{ Comorbidities } \\
\hline & & $\overline{\mathbf{M}}$ & $\mathbf{F}$ & $51-60$ & $61-70$ & $71-80$ & $81-90$ & $\overline{\mathbf{C H F}}$ & T2DM & Asthma & HTN & Dep. & Anx. & Ins. \\
\hline British & 10 & 7 & 3 & 3 & 2 & 4 & 1 & 3 & 2 & 3 & 3 & 5 & 2 & 1 \\
\hline Greek & 7 & 6 & 1 & 1 & 3 & 3 & 0 & 3 & 2 & 0 & 2 & 3 & 2 & 1 \\
\hline Dutch & 8 & 1 & 7 & 6 & 2 & 0 & 0 & 1 & 1 & 1 & 0 & 0 & 1 & 0 \\
\hline Irish & 7 & 3 & 4 & 2 & 2 & 2 & 1 & 1 & 2 & 5 & 1 & 1 & 1 & 4 \\
\hline Total & 32 & 17 & 15 & 12 & 9 & 9 & 2 & 8 & 7 & 9 & 6 & 9 & 6 & 6 \\
\hline $\begin{array}{l}\text { Percentage of } \\
\text { total }\end{array}$ & NA & 53.1 & 46.9 & 37.5 & 28.1 & 28.1 & 6.3 & 25.0 & 21.9 & 28.1 & 18.8 & 28.1 & 18.8 & 18.8 \\
\hline
\end{tabular}

The sources of listed evidence complemented each other allowing for triangulation to establish credibility within and across stakeholders.

\section{Methods (interview process)}

The focus groups and interviews were conducted in corresponding clinical sites. A total of five interviewers were involved ( 2 in the UK and 1 in each other country). All interviewers were members of the WELCOME project consortium and held appropriate research qualifications or had advanced expertise in the subject area. All interviewers had a virtual meeting whereby they discussed the interview schedule and agreed with the methodology for running the focus groups/interviews.

The intercultural harmonisation during the study was ensured by having native speakers in each country conducting the corresponding interviews and approving all schedules following the English translation. Participants were informed about the inclusion/exclusion criteria for the study through participant information sheets which were translated in different languages as appropriate. With minor exceptions, interviewees did not have an established working or patient-clinician relationship with interviewers prior to study initiation.

Focus groups lasted $\sim 2$ hours. Two short questionnaires relating to medication adherence were also given to patients and carers to complete anonymously during the focus groups. The one-on-one semistructured interviews for HCPs lasted $\sim 1$ hour. All sessions were audio recorded and subsequently transcribed and translated into English.

\section{Analyses}

Thematic analysis was conducted in a manual constant comparative manner enabled by deductive and inductive processes. One member of the research team transcribed

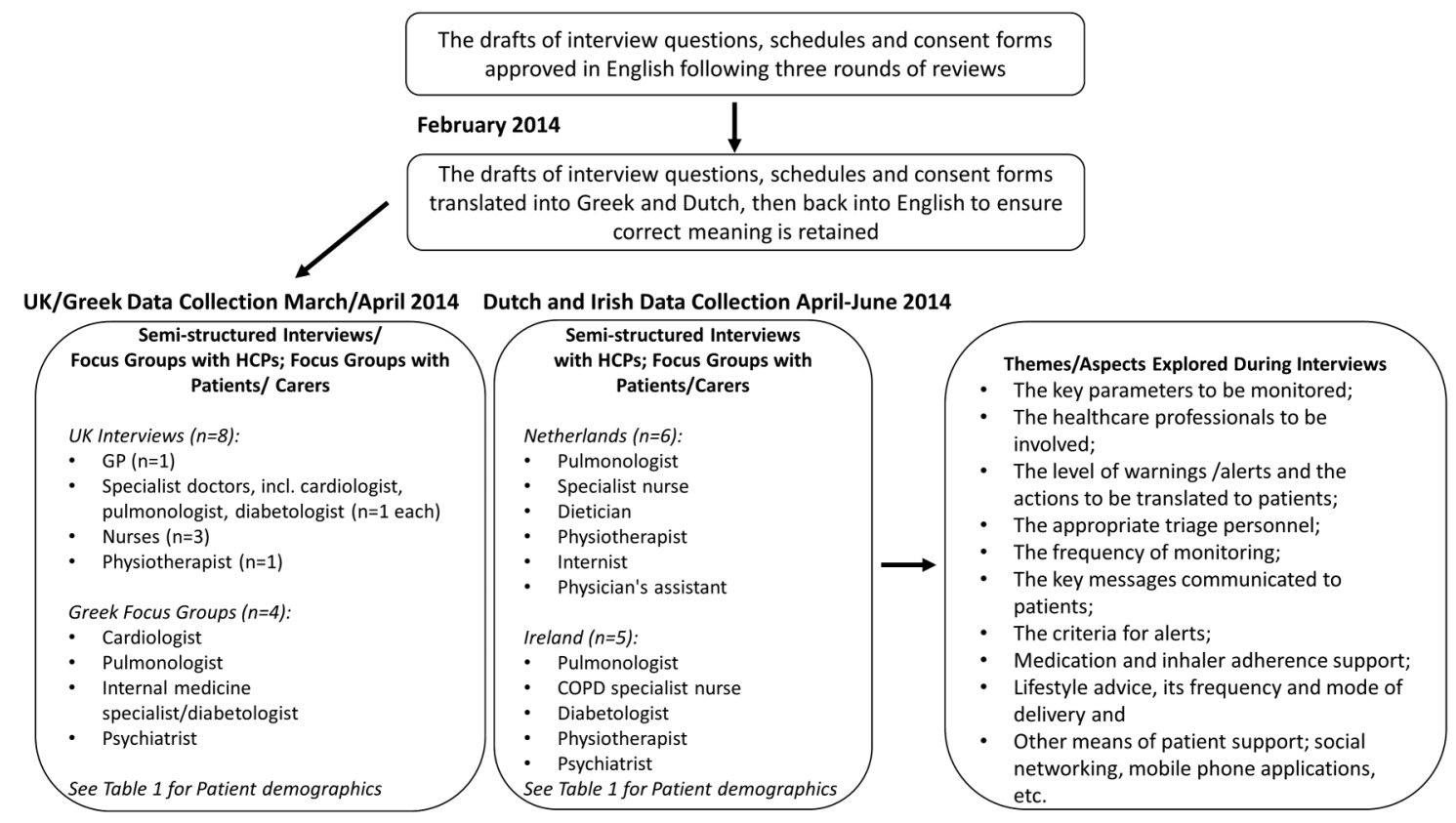

Figure 2 A flow chart depicting the preparation and data collection during the focus group sessions and semistructured interviews conducted as part of the present study. COPD, chronic obstructive pulmonary disease; GP, general practitioner/family doctor; HCPs, healthcare professionals. 
the data; however, two researchers conducted the analysis including coding. These codes were later compared, altered and modified during the consolidated analysis based on the full picture of the data as ideas developed. On the basis of these emergent codes, overarching themes from these interviews and focus groups were identified to generate overall stakeholder needs and framework recommendations. The themes derived from the three groups of stakeholders in one country were compared and contrasted with those from the other three countries to enable the individualisation of the system for each state during the future stages of development.

\section{RESULTS}

\section{Current care and challenges}

The level of satisfaction with current care varied between patients and carers of the four countries (table 2). UK patients/carers were generally happy with the current level of care and appreciated the Hot (urgent care) clinic which offered 24-hour personalised care. However, together with the Irish respondents they expected better communication between HCPs. This was echoed by HCPs of both countries who felt they lacked appropriately trained staff and resources.

Greek and Dutch patients/carers reported long waiting times when accessing healthcare. According to the Dutch patients, general practitioners (GPs) were not able to tackle some of the problems independently claiming that, in pulmonary clinics, the support was better. Poor mental health was reported as a challenge by all but the Dutch cohort.
A varying degree of non-adherence to medicines was reported by patients and carers of all countries despite the fact that a significant number of patients obtained support from their pharmacist, for example, regular checks for inhaler technique in the Netherlands. A number of reasons for this emerged, including health beliefs, generic versus brand-name drug substitution, desperation, financial issues or forgetfulness. Poor patient engagement in their own care and nonadherence to lifestyle recommendations was also identified as a challenge by HCPs in all countries.

\section{Acceptance of concepts proposed}

Most Dutch patients were sceptical about telehealth, had mixed views about the WELCOME project or the inhaler monitoring device and were cautious about the vest (table 3). A few carers were also more cautious as they thought the system would target people from specific age groups that were technology-naive.

Other cohorts of patients/carers were receptive to telehealth and thought it was creative and gave a feeling of safety. The idea of the vest was well received.

WELCOME was seen as a system that could help patients decide when to seek medical assistance, thus reducing the necessity of patients having to travel to and from the doctors. However, Dutch patients had concerns about being constantly monitored.

The majority of non-Dutch respondents felt that the inhaler monitoring device would be helpful in confirming correct use. The Dutch postulated that such a device might be a 'superfluous addition' and may only be

Table 2 A summary of current challenges reported by patients/carers involved in the study in all four countries; theme expressed/accepted is indicated as $\checkmark$; if box empty, no opinion was expressed on the theme; for Irish and Dutch data: brackets show by whom theme is expressed (patients and/or carers)

\begin{tabular}{|c|c|c|c|c|}
\hline Challenges & UK patients and carers & $\begin{array}{l}\text { Greek patients } \\
\text { and carers }\end{array}$ & $\begin{array}{l}\text { Dutch patients and } \\
\text { carers }\end{array}$ & Irish patients and carers \\
\hline Miscellaneous & $\begin{array}{l}\text { Various methods to } \\
\text { remember to take } \\
\text { medicines }\end{array}$ & $\begin{array}{l}\text { Long waiting } \\
\text { times to get } \\
\text { medical help }\end{array}$ & & $\begin{array}{l}\text { Dissatisfaction with } \\
\text { patient education }\end{array}$ \\
\hline Fragmented care & $\begin{array}{l}\text { Healthcare services and } \\
\text { communication between } \\
\text { HCPs }\end{array}$ & & & $\begin{array}{l}\text { Communication between } \\
\text { HCPs }\end{array}$ \\
\hline Adherence to medication & $\checkmark$ & $\checkmark$ & $\begin{array}{l}\checkmark \text {, inhalers especially } \\
\text { challenging }\end{array}$ & $\begin{array}{l}\checkmark \text {, inhalers especially } \\
\text { challenging }\end{array}$ \\
\hline $\begin{array}{l}\text { Many reasons for } \\
\text { patients' non-adherence } \\
\text { to medication }\end{array}$ & $\checkmark$ & $\checkmark$ & $\checkmark$ & $\checkmark$ \\
\hline $\begin{array}{l}\text { Patients' poor mental } \\
\text { health }\end{array}$ & $\checkmark$ & $\checkmark$ & & $\mathcal{J}$ (carers) \\
\hline $\begin{array}{l}\text { Limited healthcare } \\
\text { resources for patients }\end{array}$ & $\checkmark$ & $\checkmark$ & & $\begin{array}{l}\checkmark, \text { limited or delayed } \\
\text { access to resources and } \\
\text { care (carers) }\end{array}$ \\
\hline $\begin{array}{l}\text { Reported satisfaction } \\
\text { with }\end{array}$ & $\begin{array}{l}\text { 24-hour COPD care in } \\
\text { 'HOT' clinic at the UK } \\
\text { research centre }\end{array}$ & & $\begin{array}{l}\text { Pulmonary clinic, } \\
\text { pharmacist, care for } \\
\text { diabetes and CHF }\end{array}$ & $\begin{array}{l}\text { Secretion clearance } \\
\text { device }\end{array}$ \\
\hline
\end{tabular}



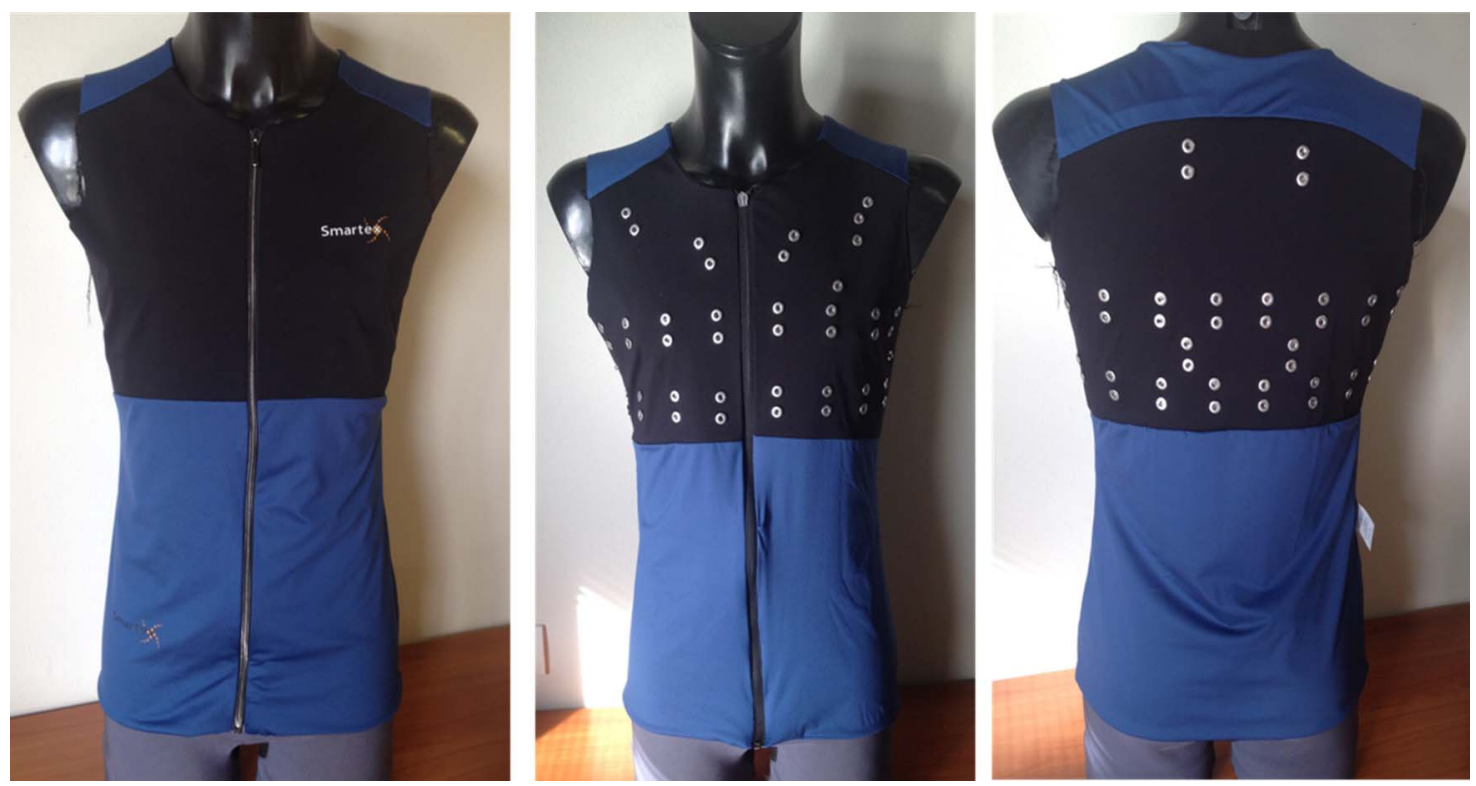

Figure 3 The proposed concept vest and sensors for Wearable Sensing and Smart Cloud Computing for Integrated Care to Chronic Obstructive Pulmonary Disease Patients with Co-morbidities (WELCOME) system. Acknowledgement Smartex s.r.I.

helpful at the start of treatment. The mobile application was welcomed by all but UK patients.

All HCPs were overall receptive to the WELCOME concepts, except two pulmonologists (Dutch and Irish) who felt that 'published results about telehealth have been varied' and that the system success depended on patients' training. A multidisciplinary effort in delivering the system and providing patients' training and advice was sought by most HCPs.

\section{The vest}

No significant patient/carer consensus was reached on the duration of vest wear (ranging from daily to wearing whenever unwell). Most respondents disagreed with continuous wear, as it may be too stressful for the patient.
The development of male/female versions of the vest was favoured by UK and Greek patients (see figure 3 for concept vest).

HCPs from all countries conformed with the fact that the vest should be worn both indoor and outdoor, and for a period of time both during day and night. They agreed that the frequency and duration of wear should be individualised taking into account factors such as adherence, frequency of exacerbations and comorbidities. All HCPs agreed that increased duration of wear should be considered postexacerbation/hospitalisation, during and postexercise.

HCPs proposed a number of different ways the biosignals' sensors should be located in the vest. For respiratory sensors this ranged from four sensors per quadrant

Table 3 A summary of acceptance of the concepts proposed by patients/carers of all four countries involved in the study; theme expressed/accepted is indicated as $\sqrt{ }$; theme not desired is indicated as $\mathrm{x}$; if box empty, no opinion was expressed on the theme; For Irish and Dutch data: brackets show by whom theme is expressed (patients and/or carers)

\begin{tabular}{|c|c|c|c|c|}
\hline $\begin{array}{l}\text { Acceptance of the } \\
\text { overall concept of: }\end{array}$ & $\begin{array}{l}\text { UK patients } \\
\text { and carers }\end{array}$ & $\begin{array}{l}\text { Greek patients } \\
\text { and carers }\end{array}$ & Dutch patients and carers & Irish patients and carers \\
\hline Telehealth & $\checkmark$ & $\checkmark$ & Mixed (most: $\times$ and sceptical) & $\sqrt{ }$ (Patients and carers) \\
\hline WELCOME & $\checkmark$ & $\checkmark$ & $\begin{array}{l}\text { Patients mixed views, carers } \\
\checkmark\end{array}$ & $\checkmark$ (Patients and carers) \\
\hline The vest & $\checkmark$ & $\checkmark$ & $\checkmark$ & $\checkmark$ \\
\hline $\begin{array}{l}\text { The inhaler monitoring } \\
\text { device }\end{array}$ & $\checkmark$ & $\checkmark$ & $\begin{array}{l}\text { Patients: mixed views (believe } \\
\text { their technique is correct), } \\
\text { carers } \checkmark\end{array}$ & $\checkmark$ (Patients and carers) \\
\hline $\begin{array}{l}\text { WELCOME } \\
\text { application }\end{array}$ & $\times$ & $\checkmark$ & $\checkmark$ (Patients and carers) & $\begin{array}{l}\text { Patients and carers: } \sqrt{ } \text { incl. } \\
\text { educational advice that the app } \\
\text { can provide }\end{array}$ \\
\hline
\end{tabular}


and matrix-like positioning to four sensors each for basal and dorsal parts of the lungs or sensors arranged in two matrices (left and right). HCPs agreed that the classical 12-lead ECG might be suitable for cardiac monitoring together with sensors over the apex of the heart, basal parts and heart valves (opinions varied).

Primary concerns related to the vest design and use included its weight (patients/carers from all countries), availability of sizes, safety, potential skin irritation, overheating and thickness of the material (patients/carers from 2 countries each). Concerns about confidentiality, for example, whether the vest would record surrounding sounds and location detection was raised by British patients/carers.

\section{Monitoring results and parameters}

The majority of patients/carers agreed that a 24/7 manned triage service run by GPs or pulmonologists was needed whereas HCPs were not as supportive of such a service preferring a time-defined, HCP-led service and welcoming a small degree of automated triage (figure 4). They also felt that abnormal results should be sent to all HCPs involved.

Patients demanded access to the complete set of their results, and apart from Dutch respondents, the general consensus was to enable carers to have a similar degree of access as patients. HCPs felt that patients/carers should have limited access to graphically presented results.

According to HCPs, the interpretation of results should be individualised and based on local guidelines, clinical practice and predetermined early warning scoring system, for example, green/amber/red colour alerts with relevant actions according to the results.

A variety of methods to alert the patients to abnormal findings were proposed by patients/carers, with text messages and emails being the most popular. Those with access to email preferred this format and graphical representation of results. Patients and carers wished to be informed as soon as possible or at least within 24 hours if it were urgent. In other cases, the desired frequency of reports varied.

The format of communication between the triage and relevant HCPs included emails, text messages, diagrams or verbal prompts. Communication between different parties should be individualised based on each patient's clinical status, ranging from once weekly to daily and real-time.

Patients/carers were willing to take individual actions in response to any alerts. Nevertheless, some carers would prefer human intervention before their response. HCPs generally agreed for patients to initiate certain actions, such as taking extra medication, in response to alerts. Both patients and HCPs asked for non-urgent communications to include motivational or reassuring feedback/messages.

All interviewed HCPs agreed that the parameters to be monitored should be individualised based on individual comorbidities (figure 5). HCPs referred to numerous guidelines/tools that may be used for populating the parameters and assisting in monitoring and decisionmaking, such as the Modified Medical Research Council Dyspnoea Scale. No consensus on monitoring frequency was reached between HCPs.

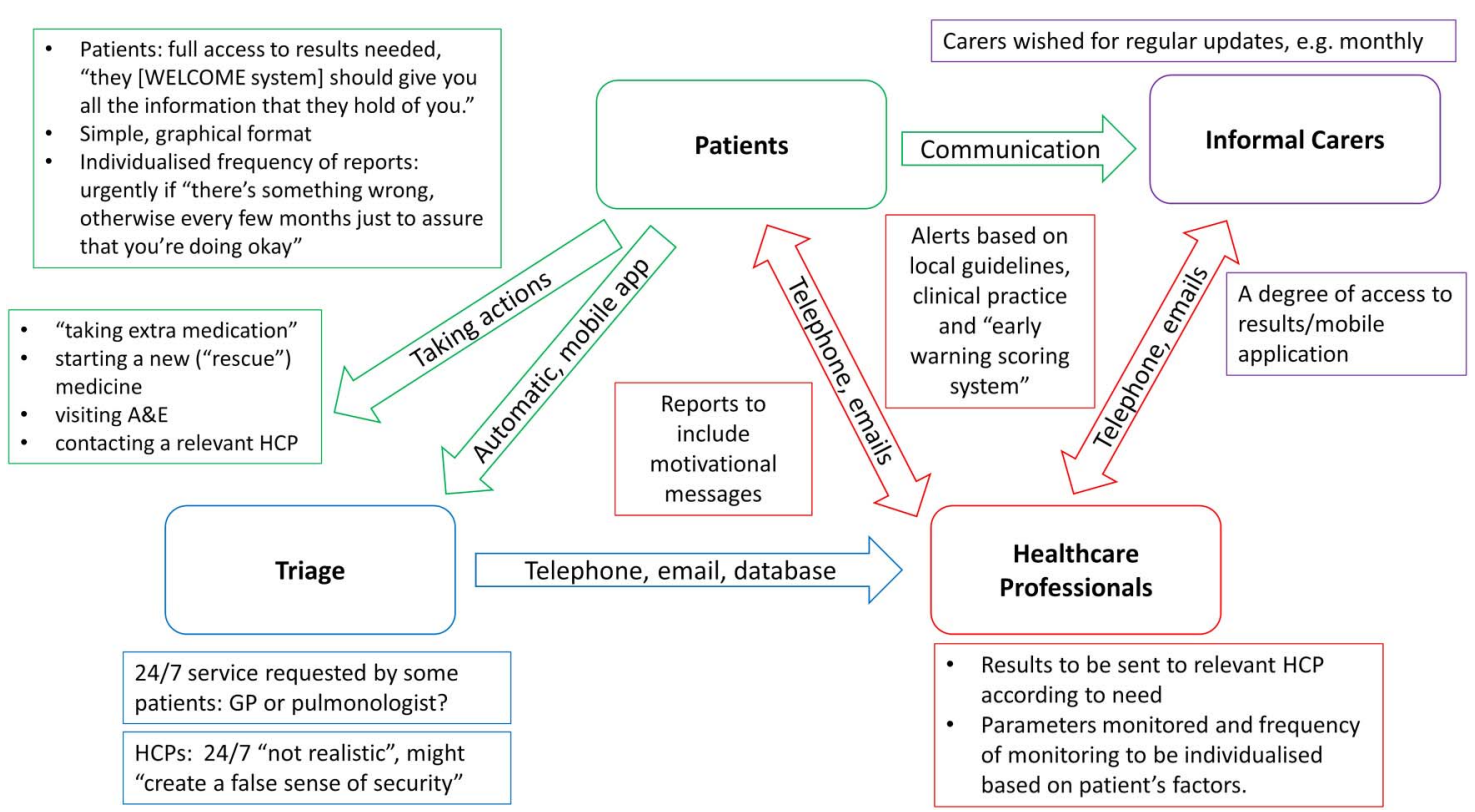

Figure 4 A summary of concepts relating to result monitoring, result display and alerts for patients as well as HCPs derived during WELCOME interviews and qualitative analysis. 24/7, 24 hours a day, 7 days a week; A\&E, accident and emergency department; App, application; GP, general practitioner; HCPs, healthcare professionals; WELCOME, Wearable Sensing and Smart Cloud Computing for Integrated Care to Chronic Obstructive Pulmonary Disease Patients with Co-morbidities. 


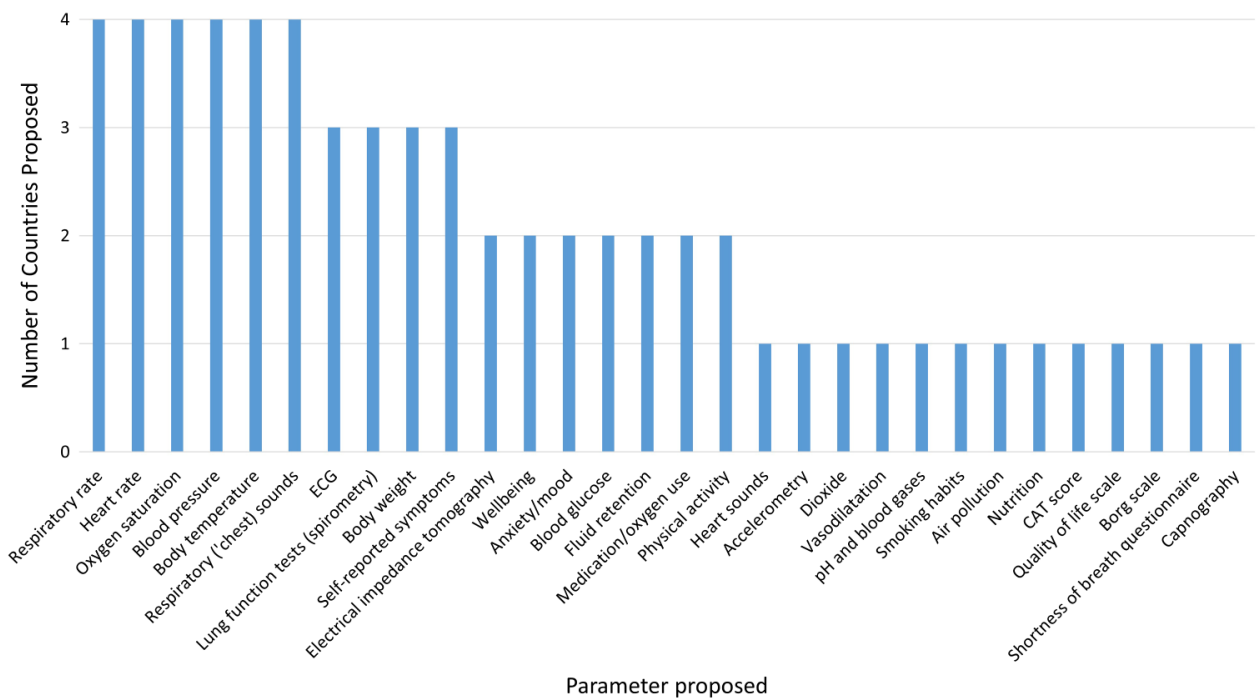

Figure 5 A range of monitoring parameters proposed by healthcare professionals interviewed, which might be included in the WELCOME system and individualised according to patient's comorbidities. CAT, chronic obstructive pulmonary disease (COPD) assessment test; WELCOME, Wearable Sensing and Smart Cloud Computing for Integrated Care to COPD Patients with Co-morbidities.

\section{WELCOME mobile phone application}

Despite generally positive reception of the application, some patients/carers as well as certain HCPs expressed concerns based on patient age preventing adaptation to new technology or resulting in fatigue.

A range of functions to be included, as part of the mobile phone application, were proposed by HCPs, patients and carers (figure 6). Patients/carers and HCPs from Greece and the UK felt that it should incorporate educational videos from reputable sources personalised depending on patients' comorbidities.
Patients/carers from all countries were interested in the diet/nutrition function of the application. All but the Dutch patients also wished for the physical activity and stress management functions whereas the mood and social network functions were positively appraised by patients/carers from two countries each, namely the UK/Ireland and the Netherlands/Ireland, respectively.

UK and Greek patients, and Irish patients/carers wanted an additional feature to enable question and answer sessions with HCPs, for example, GPs. The Greek and Dutch patients/carers proposed reminder and diary

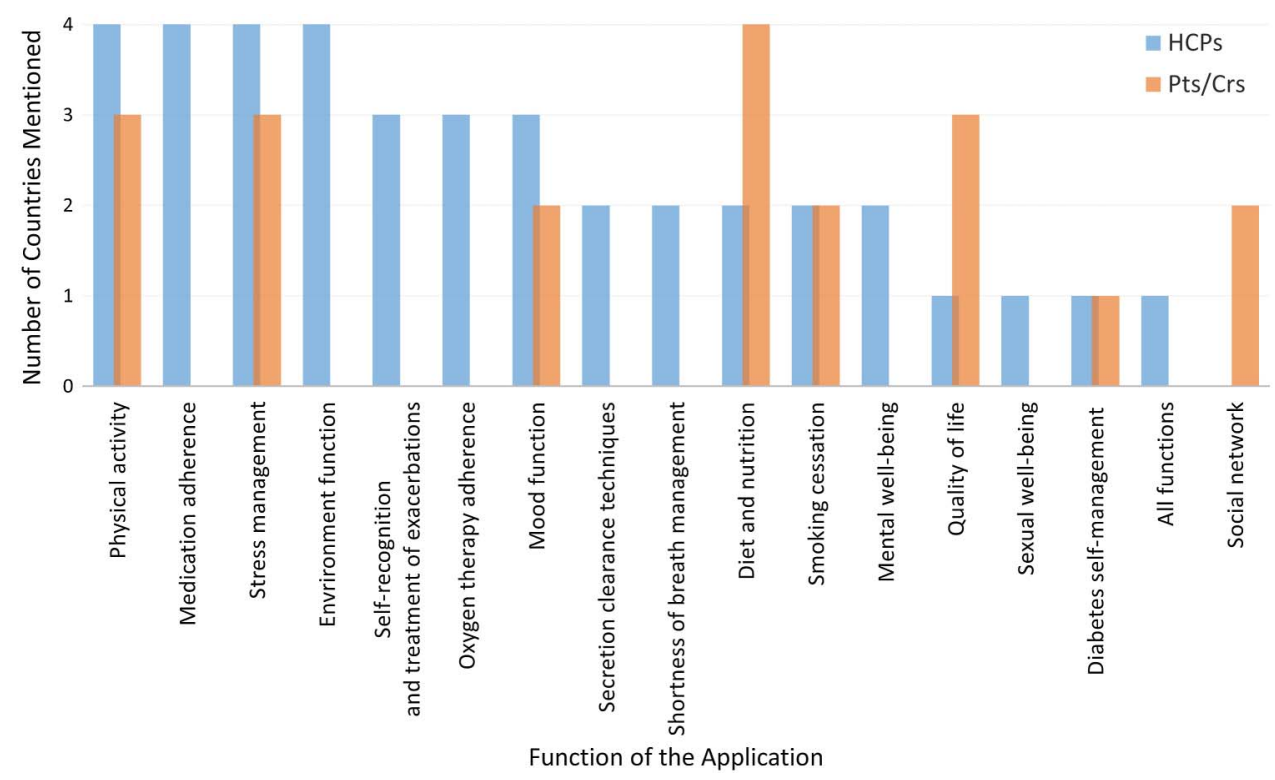

Figure 6 A range of functions proposed by healthcare professionals (HCPs) and patients/carers (Pts/Crs) of the four countries to be included as part of the Wearable Sensing and Smart Cloud Computing for Integrated Care to Chronic Obstructive Pulmonary Disease Patients with Co-morbidities (WELCOME) mobile application. 
functions that correlated with the proposals from HCPs. The Greek carers suggested an integrated accelerometer to automatically record the patient's physical activity.

The majority of functions were welcomed by HCPs from all countries who wished to be involved depending on their specialty. Clinical guidelines should be used and extra caution exercised when developing certain applications, for example, secretion clearance due to associated risks. HCPs also made suggestions to include: sexual well-being, medication and panic management functions, and a function to help detect behavioural changes.

While UK and Greek patients were happy for carers to be alerted about patients' dyspnoea, the general consensus was for carers not to have access to the functions of the application. In contrast, HCPs felt the application should be used jointly by patients and their carers depending on needs, that is, from daily to weekly considering patients' individual circumstances.

\section{DISCUSSION}

This thematic analysis provided an in depth view into the current state of care in four EU member states along with how the proposed WELCOME project could be implemented to integrate care and improve outcomes in patients with COPD. Even though these results constituted the backbone of the WELCOME system's user requirements, they can be extrapolated to aid the planning of potential technology-enabled care services.

With regards to current care received, one of the important points raised by all patient/carer cohorts centred on the challenges they face in current healthcare systems including fragmented care, lack of communication and long waiting times. Fragmented healthcare has been previously identified as a potential issue in several EU countries due to increasing morbidity and associated costs. ${ }^{18-20}$ Since WELCOME offers an alternative approach to tackling such fragmentation by providing a virtual cloud-based dynamic network between patients, carers and HCPs, it was well received by the majority of the participants.

Non-adherence to treatment emerged as one of the key themes, and some patients were very honest about how often they had forgotten or chosen not to take their prescribed medicines. Health beliefs are well documented in the literature and are known to influence the adherence rates. ${ }^{21}$ It should be noted that patients interviewed never discussed adherence issues with their HCP, while HCPs interviewed were unaware of the existence of such issues. This was not surprising as it is often widely accepted that HCPs underestimate the incidence of non-adherence among their patients. ${ }^{22}$

Poor inhaler techniques is a known reason for nonadherence, ${ }^{23}$ and a number of methods have been proposed to address this. ${ }^{24}$ The WELCOME system includes an inhaler monitoring device aimed at improving patient's technique leading to better adherence. With minor exceptions, the inhaler monitoring device proposed was considered a positive feature by users and HCPs. Information on inhaler technique and a reminder to take medicines/inhalers were among the proposed functions for the mobile application. Some of the medication-related problems identified could be tackled through appropriate patient education. ${ }^{25}$ This has been reflected in the interviews with HCPs who highlighted the importance of detailed educational sessions to train the patients and their carers about the WELCOME system.

Despite general acceptance of the WELCOME framework, the Dutch cohort of users were generally less positive about the system or its concepts regardless of their comparatively young age and familiarity with mobile technologies. The main limiting factor of the proposed vest was its comfort. Such concerns were expected from patients with COPD who already suffered from symptomatic chest discomfort. ${ }^{26}$

The majority of patients did not own smartphones and wanted to receive information via text messages. This correlated well with concerns expressed by HCPs about ability of patients to engage with the WELCOME system or the mobile application. While such limitations may need to be considered when recruiting participants for the validation study, they should not constitute the exclusion criteria. Most patients demonstrated their enthusiasm about WELCOME regardless of the level of IT skills. Similar to other studies, ${ }^{27}$ this suggests that technology-naïve patients/carers should not be excluded from opportunities to enhance their health using novel technologies based on their lack of prior experience. Instead, non-patient factors, such as poor mobile or internet reception, or technical malfunctions, may need to be considered and addressed as potential barriers to system development. ${ }^{13}$

Most HCPs in this study welcomed the system, however, with a defined monitoring time. This contradicts the literature that shows resistance from frontline staff due to perceived additional workload that telemonitoring may introduce, ${ }^{28}$ a negative perceived impact on clinician-patient relationship, ${ }^{29}$ or due to potentially unclear benefits of telemonitoring. ${ }^{13}$ The latter was only expressed by two pulmonologists in this study.

The results show that an individualised frequency and duration of vest wear and monitoring should be chosen for each patient, particularly for patients with COPD whose daily lifestyle is often affected by the disease itself. $^{30}$ This may also be influenced by factors such as the history of exacerbations and the diagnosed disease stage. Therefore, patients should be involved when the schedule of self-monitoring is decided and should be consulted at each stage of vest design.

Parameters' monitoring and feedback brought up a significant amount of debate. While some patients and most HCPs agreed for carers to have access to vital statistics, others were quite reluctant due to the burden for carers and/or lack of privacy. This was not unexpected 
since the relationships between patients with COPD and carers are often complex. ${ }^{31}$ The suggestion might be for carers' access to the results to be personalised in agreement with the patients.

In terms of alerts, HCPs felt that these also need to be generated in an individualised fashion. Clinical teams might thus consider using retrospective data from each clinical site based on their patients in order to identify the level of change/thresholds and to develop a 'traffic light'-based algorithm to be used for alerts. A threshold average (different for every parameter) will mark a minor deviation from the personal baseline, whereas other thresholds will mark major abnormalities.

Patients mostly preferred doctors to receive and screen alerts, and wanted access to their results to view their progress. However, some also wanted pharmacists, physiotherapists and nurses to be responsible for managing/checking their monitoring parameters, thus suggesting that all HCPs should have access to data, as was also emphasised by most HCPs interviewed.

Unless urgent, most patients and HCPs wanted to receive results regularly and requested positive motivational or reassurance feedback. It has been reported that the provision of such information may enhance physical activity. ${ }^{32}$

The ability of patients with COPD to self-manage exacerbations is known to improve quality of life and reduce hospital admissions. ${ }^{33}$ WELCOME users were happy to adhere to action plans based on alerts or automated advice; however, self-management advice should be appropriately formulated in a language that is sensitive to patients' needs. Furthermore, HCP-led support and education for service users is of paramount importance, particularly at the start of system implementation to ensure optimal uptake of self-management strategies. $^{34}$

Patients were less receptive to the smartphone application. It might have been perceived as an add-on compared with the vest, which may have been perceived as a life-saving measure. Patient's limited interaction with technology was one factor that was highlighted as influencing their acceptance of the application. However, other factors including socio-demographics, health-related factors or level of education may have had an influence. ${ }^{35} 36$

HCPs emphasised that the range of application functions should offer patients a choice depending on their needs without jeopardising their autonomy. HCPs from all four countries asked for the environment (eg, weather update) and medication adherence functions, the latter fitting well with adherence issues identified by patients/carers.

Diet, physical activity, smoking cessation and mood and stress management functions were preferred by HCPs and patients/carers. It is known that as many as $20 \%$ of patients with COPD suffer from depression, ${ }^{37} 38$ but they do not always seek adequate help despite an increased risk of related morbidity and mortality. ${ }^{38} 39$
Therefore, the WELCOME application will include a tool to discretely assess mood while providing education about its impact on health. Patients with COPD are known to be relatively socially isolated with their condition, ${ }^{40}$ thus it was not surprising that patients/carers requested the development of the social network function.

Overall, HCPs, patients and carers were very receptive to the WELCOME framework proposed and were happy to engage in it constructively. A number of themes have been derived during the interview process with a range of stakeholders and have been developed into appropriate recommendations through triangulation. Most importantly, our study demonstrated the need to personalise and integrate different parts of the system: the vest, the mobile application and various external devices. This is particularly important in light of the literature which shows that neither regular monitoring of physiological signs (eg, oxygen saturations) nor patientsubmitted daily electronic reports can reduce the frequency of COPD exacerbations alone. ${ }^{13}$

The recommendations presented in this paper will be considered in the later stages of system development and design. While the backbone of the system developed should be based on the recommendations derived, the specifications of the system will need to be adjusted to each participating EU member state based on their individual healthcare system and needs of the service users. As part of this process, any output of the vest components proposed (eg, ECG or oxygen saturations) should be mapped using a predetermined algorithm 'traffic light' system in a manner similar to that previously described. ${ }^{41}$

The cost-effectiveness and cost-utility of the system will also have to be evaluated to determine the core components needed (eg, the application functions) and the extent of personalisation to meet the individual's needs while still remaining cost-effective. ${ }^{42}$ This needs to be compared with structured systematic approaches ${ }^{43}$ or simple face-to-face educational interventions ${ }^{44}$ which may lead to benefits similar to those of advanced technologies.

The recommendations outlined should be interpreted with caution due to the limited number of participants interviewed (particularly elderly patients over 80 years of age) and differences in the interview process between the users and providers of healthcare services. The study also did not take into account the views of tax payers and service commissioners, which should be considered as part of the costing exercise. In addition, only one GP was involved in the interview phase despite the fact that GPs might have to lead the system implementation in primary care setting.

Author affiliations

${ }^{1}$ Faculty of Science, Engineering and Computing, Kingston University, Kingston-Upon-Thames, UK

${ }^{2}$ Department of Research and Education, ClRO+, Centre of Expertise for Chronic Organ Failure, Horn, The Netherlands 
${ }^{3}$ Pulmonary Clinic, General Hospital G.P. Papanikolaou, Thessaloniki, Greece ${ }^{4}$ Chest Clinic and Research and Development, Croydon University Hospital, Croydon, UK

${ }^{5}$ RCSI Education \& Research Centre, RCSI, Dublin, Ireland

${ }^{6}$ Research and Development, Smartex s.r.l, Pisa, Italy

${ }^{7}$ Research and Development, Exodus Information Technology S.A, Athens, Greece

\section{Twitter Follow Vilius Savickas at @viliussavickas}

Contributors RK and SN-G contributed to the study design, data analysis and drafting of the manuscript. VS contributed to the data analysis and drafting of the manuscript. MAS, EK, RWC, JC, BP and AWV contributed to the study design and drafting of the manuscript. RS, ND, RP, NP, EP, SD and AR contributed to the study design.

Funding This work was supported by the European Commission under the Information and Communication Technologies (ICT) 7th Framework Programme grant number FP7-611223.

Competing interests None declared.

Ethics approval This study was approved by the: Beaumont Hospital Ethics (Medical Research) Committee (Dublin, Ireland), Scientific Board of the G. Papanikolaou General Hospital (Thessaloniki, Greece), Medical Research Ethics Committees United (Nieuwegein, the Netherlands) and Croydon Health Services NHS Trust Information Governance (London, UK).

Provenance and peer review Not commissioned; externally peer reviewed.

Data sharing statement Detailed interview transcripts are stored at Kingston University and available on request.

Open Access This is an Open Access article distributed in accordance with the Creative Commons Attribution Non Commercial (CC BY-NC 4.0) license, which permits others to distribute, remix, adapt, build upon this work noncommercially, and license their derivative works on different terms, provided the original work is properly cited and the use is non-commercial. See: http:// creativecommons.org/licenses/by-nc/4.0/

\section{REFERENCES}

1. Medical directorate. Overview of potential to reduce lives lost from Chronic Obstructive Pulmonary Disease (COPD). NHS England 2014. https://www.england.nhs.uk/wp-content/uploads/2014/02/rmfs-6.pdf (accessed online Aug 2016).

2. British Thoracic Society and British Lung Foundation. Ready for Home: improving hospital discharge care for people living with COPD. 2011. https://www.brit-thoracic.org.uk/document-library/ clinical-information/copd/ready-for-home-improving-hospitaldischarge-care-for-people-living-with-copd/ (accessed online Aug 2016).

3. Andenaes R, Kalfoss MH, Wahl AK. Coping and psychological distress in hospitalized patients with chronic obstructive pulmonary disease. Heart Lung 2006;35:46-57.

4. Marques A, Jácome C, Cruz J, et al. Family-based psychosocial support and education as part of pulmonary rehabilitation in COPD: a randomized controlled trial. Chest 2015;147:662-72.

5. Rutten FH, Cramer MJ, Grobbee DE, et al. Unrecognized heart failure in elderly patients with stable chronic obstructive pulmonary disease. Eur Heart J 2005;26:1887-94.

6. Mannino DM, Thorn D, Swensen A, et al. Prevalence and outcomes of diabetes, hypertension and cardiovascular disease in COPD. Eur Respir J 2008;32:962-9.

7. Kunik ME, Roundy K, Veazey $\mathrm{C}$, et al. Surprisingly high prevalence of anxiety and depression in chronic breathing disorders. Chest 2005;127:1205-11.

8. $\mathrm{Ng} \mathrm{TP}, \mathrm{Niti} \mathrm{M}, \mathrm{Tan} \mathrm{WC}$, et al. Depressive symptoms and chronic obstructive pulmonary disease: effect on mortality, hospital readmission, symptom burden, functional status, and quality of life. Arch Intern Med 2007;167:60-7.

9. Steventon A, Bardsley M, Billings J, et al. Effect of telehealth on use of secondary care and mortality: findings from the Whole System Demonstrator cluster randomised trial. BMJ 2012;344:e3874.

10. Nicolucci A, Cercone $S$, Chiriatti A, et al. A randomized trial on home telemonitoring for the management of metabolic and cardiovascular risk in patients with type 2 diabetes. Diabetes Technol Ther 2015;17:563-70.
11. Thokala $\mathrm{P}$, Baalbaki $\mathrm{H}$, Brennan $\mathrm{A}$, et al. Telemonitoring after discharge from hospital with heart failure: cost-effectiveness modelling of alternative service designs. BMJ Open 2013;3:e003250.

12. Dawson $G$, Collinge M, Roberts J, et al. P27 the use of telemonitoring to assist in the early supported discharge for patients admitted with an exacerbation of COPD. Thorax 2014;69:A89.

13. Pinnock $\mathrm{H}$, Hanley J, McCloughan L, et al. Effectiveness of telemonitoring integrated into existing clinical services on hospital admission for exacerbation of chronic obstructive pulmonary disease: researcher blind, multicentre, randomised controlled trial. BMJ 2013;347:f6070.

14. Williams V, Price J, Hardinge $\mathrm{M}$, et al. Using a mobile health application to support self-management in COPD: a qualitative study. Br J Gen Pract 2014;64:e392-400.

15. Segrelles Calvo G, Gómez-Suárez C, Soriano JB, et al. A home telehealth program for patients with severe COPD: the PROMETE study. Respir Med 2014;108:453-62.

16. Nield M, Hoo GW. Real-time telehealth for COPD self-management using Skype. COPD 2012;9:611-19.

17. Chouvarda I, Philip NY, Natsiavas P, et al. WELCOME-innovative integrated care platform using wearable sensing and smart cloud computing for COPD patients with comorbidities. Conf Proc IEEE Eng Med Biol Soc 2014;2014:3180-3.

18. Frandsen BR, Joynt KE, Rebitzer JB, et al. Care fragmentation, quality, and costs among chronically ill patients. Am J Manag Care 2015;21:355-62.

19. Nolte E, Knai C, Hofmarcher M, et al. Overcoming fragmentation in health care: chronic care in Austria, Germany and The Netherlands. Health Econ Policy Law 2012;7:125-46.

20. Otte-Trojel T, de Bont A, Aspria M, et al. Developing patient portals in a fragmented healthcare system. Int $\mathrm{J}$ Med Inform 2015;84:835-46.

21. van Grunsven PM, van Schayck CP, van Kollenburg $\mathrm{HJ}$, et al. The role of "fear of corticosteroids" in nonparticipation in early intervention with inhaled corticosteroids in asthma and COPD in general practice. Eur Respir J 1998;11:1178-81.

22. Byerly M, Fisher R, Whatley $\mathrm{K}$, et al. A comparison of electronic monitoring vs. clinician rating of antipsychotic adherence in outpatients with schizophrenia. Psychiatry Res 2005;133: 129-33.

23. Lurslurchachai L, Krauskopf K, Roy A, et al. Metered dose inhaler technique among inner-city asthmatics and its association with asthma medication adherence. Clin Respir J 2014;8: 397-403.

24. Chan $\mathrm{AH}$, Stewart AW, Harrison J, et al. The effect of an electronic monitoring device with audiovisual reminder function on adherence to inhaled corticosteroids and school attendance in children with asthma: a randomised controlled trial. Lancet Respir Med 2015;3:210-19.

25. Incorvaia C, Riario-Sforza GG. Effect of patient education on adherence to drug treatment for chronic obstructive pulmonary disease. Ann Thorac Med 2011;6:242-3.

26. Vestbo J, Hurd SS, Agustí AG, et al. Global strategy for the diagnosis, management, and prevention of chronic obstructive pulmonary disease: GOLD executive summary. Am J Respir Crit Care Med 2013;187:347-65.

27. Lind L, Karlsson D. Telehealth for "the digital illiterate"-elderly heart failure patients experiences. Stud Health Technol Inform 2014;205:353-7.

28. Hibbert D, Mair FS, May CR, et al. Health professionals' responses to the introduction of a home telehealth service. $J$ Telemed Telecare 2004;10:226-30.

29. Fairbrother $\mathrm{P}$, Pinnock $\mathrm{H}$, Hanley $\mathrm{J}$, et al. Continuity, but at what cost? The impact of telemonitoring COPD on continuities of care: a qualitative study. Prim Care Respir J 2012;21:322-8.

30. Rodriguez Gonzalez-Moro JM, de Lucas Ramos P, Izquierdo Alonso $\mathrm{JL}$, et al. Impact of COPD severity on physical disability and daily living activities: EDIP-EPOC I and EDIP-EPOC II studies. Int J Clin Pract 2009;63:742-50.

31. Wang KY, Sung PY, Yang ST, et al. Influence of family caregiver caring behavior on COPD patients' self-care behavior in Taiwan. Respir Care 2012;57:263-72.

32. Moy ML, Weston NA, Wilson EJ, et al. A pilot study of an internet walking program and pedometer in COPD. Respir Med 2012;106:1342-50.

33. Zwerink M, Brusse-Keizer M, van der Valk PD, et al. Self management for patients with chronic obstructive pulmonary disease. Cochrane Database Syst Rev 2014;(3):CD002990.

34. Voncken-Brewster $\mathrm{V}$, Tange $\mathrm{H}$, de Vries $\mathrm{H}$, et al. A randomized controlled trial evaluating the effectiveness of a web-based, computer-tailored self-management intervention for people with 
or at risk for COPD. Int $J$ Chron Obstruct Pulmon Dis 2015;10:1061-73.

35. Or CK, Karsh BT. A systematic review of patient acceptance of consumer health information technology. J Am Med Inform Assoc 2009;16:550-60

36. Illiger K, Hupka M, von Jan U, et al. Mobile technologies: expectancy, usage, and acceptance of clinical staff and patients at a university medical center. JMIR Mhealth Uhealth 2014;2:e42.

37. Schneider C, Jick SS, Bothner U, et al. COPD and the risk of depression. Chest 2010;137:341-7.

38. Maurer J, Rebbapragada V, Borson S, et al. Anxiety and depression in COPD: current understanding, unanswered questions, and research needs. Chest 2008;134(4 Suppl):43S-56S.

39. Pooler A, Beech R. Examining the relationship between anxiety and depression and exacerbations of COPD which result in hospital admission: a systematic review. Int J Chron Obstruct Pulmon Dis 2014;9:315-30.
40. Keele-Card G, Foxall MJ, Barron CR. Loneliness, depression, and social support of patients with COPD and their spouses. Public Health Nurs 1993;10:245-51.

41. Burton C, Pinnock H, McKinstry B. Changes in telemonitored physiological variables and symptoms prior to exacerbations of chronic obstructive pulmonary disease. J Telemed Telecare 2015;21:29-36.

42. Stoddart $\mathrm{A}$, van der Pol M, Pinnock $\mathrm{H}$, et al. Telemonitoring for chronic obstructive pulmonary disease: a cost and cost-utility analysis of a randomised controlled trial. $J$ Telemed Telecare 2015;21:108-18.

43. Kainu $A$, Pallasaho $P$, Piirila $P$, et al. Increase in prevalence of physician-diagnosed asthma in Helsinki during the Finnish Asthma Programme: improved recognition of asthma in primary care? A cross-sectional cohort study. Prim Care Respir J 2013;22:64-71.

44. Rice KL, Dewan N, Bloomfield HE, et al. Disease management program for chronic obstructive pulmonary disease: a randomized controlled trial. Am J Respir Crit Care Med 2010;182:890-6. 